\title{
Providing truly patient-centred care: Harnessing the pragmatic power of interpreters
}

\author{
Kim Wallmach \\ Wits Language School, University of the Witwatersrand, South Africa \\ E-mail: kim.wallmach@wits.ac.za
}

\begin{abstract}
In order to achieve the aims set out in South Africa's National Policy on Quality in Health Care (2007:4), the gap between standards and actual practice must be measured, reduced, and ultimately, eradicated. One of the most obvious gaps in our health service is the failure to ensure that patients and healthcare professionals understand each other. Without successful communication, the provision of quality patient-centred care will always hang in the balance. Healthcare professionals in South Africa have to improvise when treating patients who do not speak their language - generally by using ad-hoc interpreters, who may be nurses, refugees, family members, or even children. A number of studies (Cambridge 1999, Meyer et al. 2003, Penn 2007) have found that using ad-hoc interpreters to overcome language barriers is often problematic. In this article, a specific intervention is described which takes the form of a professional development workshop for counsellors and community workers working with refugees, aimed at reaching a better understanding of how to work with interpreters. An ad-hoc interpreter participated in a role play with a therapist and refugee client, and was then substituted by a professional liaison interpreter. The workshop participants (who could not understand French or Lingala, the languages spoken by the refugee client and the refugee interpreter) commented on the differences between the two interpreters' performances and their impressions of the power dynamics between participants, caused in part by factors such as positioning and eye gaze. The researcher then conducted a conversation analysis to supplement these findings. Aspects considered include the effect of procedural factors (control of turn length, attribution of roles and briefing of participants, use of the first person, memory management and overload) as well as linguistic aspects of the communication flow. The analysis indicated that it was the ad-hoc refugee interpreter's lack of knowledge regarding the procedural aspects of the interpreting process that impacted most on the communication flow, rather than any possible transference or re-telling of her own story, as has previously been indicated in the literature. The trained interpreter's linguistic knowledge and awareness of procedural aspects led to smoother communication between participants. It is recommended that interpreters in therapeutic contexts be trained to participate as active co-participants so that they may control turn duration, be aware of role attribution and positioning, and extend their memories to enable them to interpret accurately in the long consecutive mode.
\end{abstract}

Keywords: healthcare interpreting, refugee interpreting, professional development 


\section{Introduction: How do we achieve quality patient-centred care in South Africa?}

The National Policy on Quality in Health Care (2007:4) sets out the main objectives of Government to assure quality in healthcare in South Africa's public and private sectors. The national aims for improvement include, but are not limited to:

- Addressing access to health care;

- Increasing patients' participation and the dignity afforded to them;

- Reducing underlying causes of illness, injury, and disability through preventive and health promotion activities;

- Ensuring the appropriate use of health care services, and

- Reducing health care errors (adverse events).

In order to achieve these aims, it is important to measure the gap between standards and actual practice, and work out ways to close the gap. One of the most obvious gaps in South Africa's health service, which underlies all of the healthcare objectives mentioned in the policy, is the failure to ensure that patients and healthcare professionals understand each other. Without successful communication, none of the goals mentioned above can be achieved, and the provision of quality patient-centred care will always hang in the balance. Despite its obvious importance as a medium of communication, interpreting between languages is not explicitly mentioned in any healthcare policy in South Africa to date, a clear oversight given the fact that lack of access to quality healthcare as a result of language and cultural barriers is a problem that countless South Africans face (Anthonissen 2010, Deumert 2010, Pfaff and Couper 2009). In the absence of an official public service interpreting agency which could source trained interpreters, medical professionals in South Africa have to improvise when treating patients who do not speak their language - generally by using ad-hoc interpreters, who may be nurses, family members, or even children.

A number of studies undertaken both in South Africa and internationally (Cambridge 1999, Meyer et al. 2003, Penn 2007) have found that using ad-hoc interpreters to overcome language barriers in healthcare is often problematic. Relatives of patients acting as interpreters have an obvious difficulty in remaining impartial, possess little to no medical knowledge and often an insufficient command of English, whereas using nurses as ad-hoc interpreters adds to the workload of already overburdened nursing staff, who have also not been screened for language proficiency or trained as interpreters. However, most studies on the topic seem content to document the rather unsatisfactory situation confronting healthcare professionals using ad-hoc interpreters, rather than trying to find solutions to improve the situation. The same applies to mental healthcare contexts. The fact that most therapists are forced to "make do" when an interpreter is needed (Holland and Penn 1995, Friedland and Penn 2003) is simply accepted, and the problems accompanying the "ad-hoc approach" (Roberts 1997) are merely described and documented.

This article is part of a larger research project at the University of the Witwatersrand, entitled the Language in the Caring Professions Project, which aims firstly at evaluating language practices within the caring professions in selected public/private hospitals in Johannesburg, and secondly at advocating for structured change in language practices through awareness-raising and training of healthcare professionals in the optimal use of language practitioners, as well as the use of trained interpreters or translators, where practically possible. Accordingly, this study 
explores one specific type of intervention - the use of professional development workshops for therapists and community workers, aimed at reaching a better understanding of how to work with interpreters successfully and maximise patient satisfaction. Ad-hoc interpreters participated in role play with a healthcare professional, and were then substituted by a professional liaison interpreter. The workshop participants then analysed the differences between the two interpreters, and gave their impressions of the role attribution by participants, the effect of interpreter alterations of the pragmatic meaning of utterances, procedural factors and power dynamics.

\section{Liaison interpreting in mental health contexts}

Mental health is still the Cinderella of healthcare in South Africa. Three quarters of the people in South Africa who suffer from a mental health disorder are not getting the care they need. (Kahn 2013). According to a Department of Health briefing of Parliament in June 2013, the public sector faces a severe shortage of psychiatrists and psychologists:

Only $14 \%$ of the 2,692 clinical psychologists registered with the Health Professions Council of SA are working in the public sector - just 0.32 psychologists per 100,000 of the population and 0.28 psychiatrists per 100,000 . (Kahn 2013)

Added to this is the language barrier, which is a very real issue (Drennan 1998, 1999; Mouyis n.d.). Overburdened therapists must counsel their clients with the aid of an interpreter who is generally not trained. Effective therapy using an interpreter depends on a number of factors, not least of which is the training or experience the interpreter has in the interpreting process. One of the common misconceptions is the idea that if someone "knows how to speak" a language, they will be able to interpret. This is not necessarily the case. The interpreter needs to be trained to interpret in order to avoid the tendency to "filter" information. For instance, Marcos (1979) discusses three major sources of distortion which can cause clinically significant "filtering": deficient linguistic or interpreting skills, lack of knowledge and sophistication in mental health, and interpreter attitudes toward either the client or the clinicians.

Assuming the interpreter is qualified to work in a clinical setting, a second, vital factor which contributes to the success or otherwise of the interpreted counselling process is the therapists' knowledge of how to work with an interpreter. The addition of an interpreter into the traditionally dyadic therapeutic relationship between therapist and client is known to alter the process of psychotherapy (Miller et al. 2001:5) The process is very different when working via a third person than when working one-on-one with the client, and the therapist must recognise these differences and be willing to make adjustments for them. As Hamerdinger and Karlin (2003:2) put it:

When the skilled clinician is teamed with a highly qualified interpreter, both professionals will be constantly monitoring each other for [...] shading and skewing of the message. The difficulty lies when the therapist is not experienced in using interpreters and not aware of the effects of the interpreter on the therapeutic relationship. Considerations of alliances become critical. Is the client allied with the therapist or the interpreter? More importantly, is the interpreter allied with the therapist or the client? Do both the client and the therapist trust the interpreter and the interpretation? Being unprepared to deal with these dynamics will make the work less effective. 
There are several schools of thought as regards the appropriate role of interpreters in mental health sessions (cf. also Pöchhacker 2006). Several authors believe that interpreters should be seen as co-therapists, and should therefore be trained in social work, psychotherapy and psychiatry (Westermeyer 1990, Hatton 1992, Pentz-Moller and Hermansen 1991). Mudarikiri (2003, in Bot 2005:13) argues that interpreters should be seen as "bilingual health workers or social care professionals in their own right [...] with whom one can, together with the patient, jointly seek out culturally appropriate solutions to the service-users' difficulties". Advocates of the interpreter-as-co-therapist model are also of the view that the interpreter should be informed in advance about the nature of the therapy, and that the consultation should be evaluated with the therapist after the session.

Others point out that an interpreter trained as a therapist might be less effective as a translator (i.e. in transferring the message from one language to another) in that there may be a tendency to influence the process of counselling with the interpreter's own ideas about how the therapy should proceed. For this reason, several authors (Acosto and Cristo 1981 and Garcia-Peltoniemi and Egli 1988, both cited in Bot 2005:13) emphasise that the interpreter must distance him/herself from the therapeutic process and limit him-/herself to representing what is said as accurately as possible.

A third position (to which I subscribe) is that interpreters should be seen as active coparticipants in an interaction (cf. Roy 2000), and acknowledge their influence on that interaction. Interpreters are not neutral, and cannot be seen as mere conduits or language channels, and thus the interpreter-as-translator model cannot hold water. As previous research shows (Wallmach 2008), it is extremely dangerous to allow even trained interpreters to interpret in a therapeutic context without any knowledge of the therapeutic process. Nevertheless, in my view, the interpreter-as-co-therapist model is not tenable either, since the exigencies of the interpreting process are such that an interpreter has enough to concentrate on in managing their role effectively and facilitating the communication accurately from one language to another without having to worry about directing the counselling process in addition to this. I therefore concur with Bot (2005:18) that the model of "interpreter-as-active-translator/co-participant" is the most suitable one: it does not lead to the role confusion of the co-therapist model, while it recognises the presence of the interpreter. It should be stressed that there is an important distinction between viewing the interpreter as co-therapist and as co-participant. Health professionals might reject the conduit model as de-humanising and, in wishing to acknowledge the influence of the interpreter as a professional, turn to the label of "co-therapist", whereas in fact it is sufficient to recognise interpreting itself as a profession, and the interpreter as an active representative of that profession.

\section{Interpreting for refugees in mental health contexts}

A survey conducted in 2003 by the Community Agency for Social Enquiry (CASE) (Belvedere et al. 2003, in Higson-Smith et al. 2006) on refugees and asylum seekers in South Africa included approximately 1,500 refugees and asylum seekers living in the cities of Johannesburg, Pretoria, Cape Town and Durban. Refugees participating in this study originated from Angola, the Democratic Republic of the Congo, Somalia, Burundi, Congo-Brazzaville, Ethiopia, Rwanda, Uganda, Cameroon, Sierra Leone and Sudan. Approximately $60 \%$ of the participants in this study were asylum seekers, and over half the total sample had waited more than four years for their status to be determined. The average age of the asylum seekers was 31 years and 
approximately half were married. The median income of this group was R650-00 per month. While this study was not focused specifically on services to asylum seekers and refugees, it was noted that $60 \%$ of the sample had tried to make use of emergency healthcare while in South Africa. Of those who had tried, $17 \%$ reported having been denied care. One can only imagine the mental situation of at-risk minorities such as refugees and asylum seekers, whose very existence and livelihood is threatened.

While interpreting within the mental health setting has been the focus of considerable clinical discussion, there is little research available on the use of interpreters with refugee clients, particularly in the South African context. Given the general shortage of therapists, it is hardly surprising that counselling for refugees in South Africa also suffers from a lack of capacity. In addition, given the language barrier, the unfortunate situation is that overburdened therapists most often counsel their clients with the aid of an interpreter who is generally not trained, and is often a refugee. Miller et al. (2001:6) emphasise that psychotherapy with political refugees differs from psychotherapy with other clients who might require an interpreter, and the problem is compounded if the interpreter is also a refugee. For instance, refugees have often been exposed to extreme violence, deprivation and persistent psychological trauma, and may subsequently develop post-traumatic stress disorder (Weiten 1995). They have also experienced multiple losses - from social networks to personal possessions - and are displaced from a familiar environment that supports their role and place in society and thus their ability to function within that society (Miller et al. 2002). The stories of trauma, separation and loss are likely to make the therapeutic process emotionally intense, especially for the interpreter, who may have undergone similar experiences in the past. Figley (1995:xiv) uses the term "compassion stress" to describe how professional caregivers, therapists in particular, experience "the natural behaviours and emotions that arise from knowing about a traumatizing event experienced by a significant other - the stress resulting from helping or wanting to help a traumatised person". Not only do interpreters "know about" events, they are responsible for conveying the emotional content and effect of any narrative, often through the use of the first person, which could potentially increase the likelihood of compassion stress. Interpreting involving work in highly sensitive and emotive situations, directly witnessing traumatic events or interpreting the telling of traumatic events can certainly exponentially increase the stress experienced by an interpreter (Hetherington 2011). Interpreters are generally trained to think that they are neutral, whereas the opposite is very possibly true. In many liaison or community interpreting settings, particularly in the case of untrained interpreters, an alliance develops between the interpreter and the non-English-speaking person, since they share a common language and common community. According to Hamerdinger and Karlin (2003:5):

This skew is potentially dangerous in the mental health setting. Issues of co-dependency on the part of the interpreter, transference issues, counter transference, and borderline behaviour on the part of the client, can all subtly undermine the therapy. Because the therapist and the interpreter are working together towards a specific therapeutic goal, it is critical that the alliance be between the interpreter and the clinician. The consistent use of pre- and post-conferencing helps ensure this happens, and that it is therapeutically productive.

Despite the fact that ad-hoc interpretation in healthcare contexts has been shown to be problematic, the assumption seems to be that using ad-hoc interpreters is simply the norm, at least in South Africa. The fact that most therapists are forced to "make do" when an interpreter 
is needed (Holland and Penn 1995, Friedland and Penn 2003) is simply accepted, and the problems accompanying the "ad-hoc approach" (Roberts 1997) are simply described and documented. However, our approach within this project was slightly different - to empower healthcare professionals through professional development workshops in order to achieve a clearer understanding of the skills involved in interpreting from a professional perspective, and to determine how a mediated interview using a professional interpreter might better achieve the aims of the professional than when using an ad-hoc interpreter.

\subsection{Professional development workshop participants and objectives}

A workshop was organised at a trauma counselling centre in January 2013. This workshop was attended by three interpreter trainers and 22 counsellors/community workers, including two untrained refugee interpreters who spoke Lingala, French and English. None of the counsellors/ community workers spoke either French or Lingala. The instructors had no control over the number of participants per group, who were invited to attend by the counselling centre. The stated aim of the workshop was to exchange ideas on interpreting, which the participants had not reflected on previously. Some of the counsellors expressed a desire to learn to "navigate the spaces between counsellor and interpreter", to "learn something new that might help bridge the language barrier", to "know what is expected of an interpreter", and/or to see how to "work with the interpreter as co-counsellor". The trainers' aim was to impart some knowledge of certain basic aspects of interpreting practice, such as the importance of an interpreting brief, the importance of impartiality as well as confidentiality and accuracy, and sharing techniques on how to make the communication flow more smoothly. Conversely, the trainers wished to learn from the professionals which particular context-specific skills an interpreter might need, and how standard interpreter training should be modified to accommodate the real-life practice of therapeutic contexts.

Two role plays were performed during the workshop in order for the workshop participants to compare the differences between a counselling session where an ad-hoc interpreter was used, and a counselling session where a professional interpreter was used. One of the ad-hoc interpreters (herself a refugee) was asked to participate in a counselling session role play with an English-speaking therapist and a Lingala/French-speaking refugee. A second role play was then conducted with the same therapist and refugee client, but using a professional French/English interpreter from Cameroon who had received more than a year's training in liaison and conference interpreting.

\section{Methodology and analysis}

The analysis of the role plays was conducted in two parts. In the first part, the workshop participants (who could not understand French or Lingala) observed the two role plays and gave oral feedback, analysing the differences between the two interpreters, and giving their impressions of the role attribution by participants and the power dynamics caused in part by factors such as positioning and eye gaze. For the second part of the analysis, the researcher transcribed both role plays with the assistance of a French transcriber, and provided an indicative English gloss of the French sections. She then conducted a conversation analysis to supplement the findings of workshop participants in order to determine the effects of procedural factors (such as the control of turn length, conscious attribution of roles and briefing of participants, memory management and overload) as well as the effect of linguistic aspects on 
the communication flow. Conversation Analysis (CA) was deemed to be a suitable approach to take to explore the dynamics of an interpreted therapeutic interview, since the approach focuses on naturally occurring data in order to describe the detailed and intricate analysis of turns, topics and patterns of interactive collaborative language (Friedland and Penn 2003:96). As Lesser and Perkins (1999:91) note, "[s]ocial interaction is seen as an operation achieved by its participants rather than something static arising from internalised rules, developed through socialisation".

In the therapeutic context, a key dimension is how to relate to the other's perspective. In order to deliver his or her professional view on the matter, the therapist must be able to create a rapport with the client in order to elicit the client's perspective and display understanding and sensitivity towards the client's concerns, while at the same time maintaining a professional distance from the client. A counselling session can therefore be characterised as "quasiconversational" institutional interaction - no formal turn-taking takes place, but turn design and lexical choices are important (Arminen 2005:85). Of course, these expectations must change the moment an interpreter has to mediate between the two parties, since a non-formal turntaking order is replaced by a rigid turn-taking order, with the interpreter taking every second turn at talk (Wallmach 2008). It has been shown that in ordinary interaction speakers instinctively know how to signal a turn, and that there are in fact few gaps between turns and very little overlapping speech (Jefferson 1992). However, in interpreted interaction with a trained interpreter, it is the interpreter and not the speaker(s) who manages the interaction, often signalling the end of a turn using a hand gesture (Wallmach 2008). An untrained interpreter may not be able to manage the turn length of the participants, which in turn could impact on his/her ability to remember long chunks of information contained in long turns.

Another important aspect of a therapeutic interview is the non-verbal interaction between participants. The requirement that both talk and physical action must be taken into account if we are to understand complex activity has come to be recognised by conversation analysts as well. For example, Schegloff (1987) speaks of "talk-in-interaction" and Moerman (1990, in Jordan and Henderson 1995:42) suggests that the distinction between verbal and non-verbal interaction is a total fallacy as "communication by means of pure language, without context, without body, without time, simply doesn't exist". For talk-driven interaction, the most relevant non-talk activities are gesturing and gazing, since both coordinate the talk (Jordan and Henderson 1995).

Thus, aspects such as positioning and eye gaze, role attribution and rapport between participants, turn length and turn control, and interpreting accuracy were key aspects of the analysis of the two role plays. I will begin by discussing positioning and eye gaze, since this is in fact the only aspect that was fully understood by the workshop participants, owing to the fact that they did not speak French. I will then discuss the commentary on the role plays by the workshop participants, followed by an exploration of role attribution and rapport between participants, turn length and turn control, and linguistic accuracy.

\subsection{Positioning and eye gaze}

In commenting on the differences between the refugee interpreter role play (Role Play 1 in Figure 1) and the trained interpreter role play (Role Play 2 in Figure 1), the first important difference noted was that of positioning and eye gaze, indicated in Figure 1 below. The pointed end of the ellipse indicates the most common direction of eye gaze in each role play. 


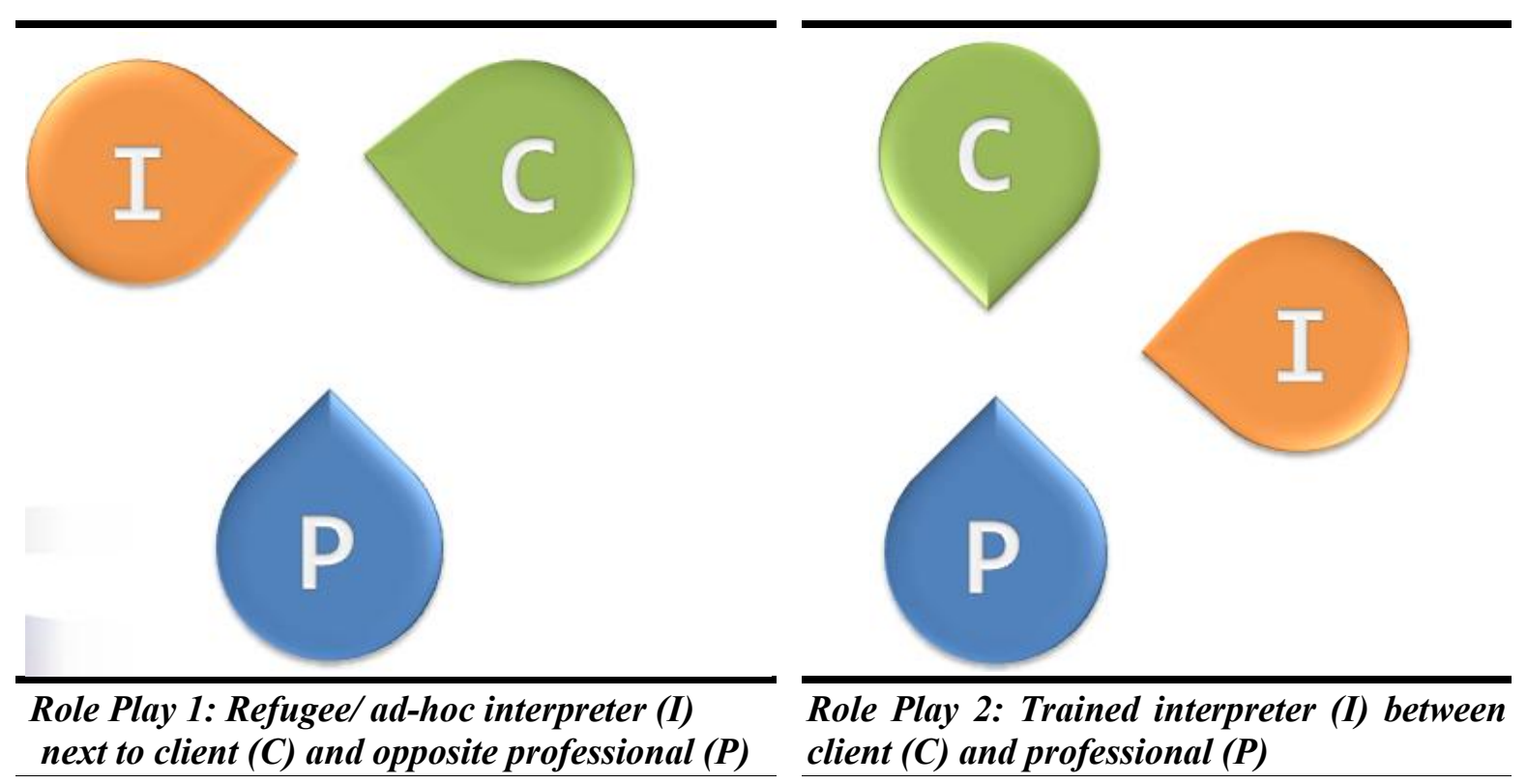

Figure 1. Differences in positioning and eye gaze

In Role Play 1, where the refugee interpreter and client were placed next to each other, facing the therapist/professional, the refugee interpreter's eye gaze was focused mainly on the client, thereby excluding the therapist to a large extent, whereas in Role Play 2, the trained interpreter positioned herself midway between the two parties, thus enabling the therapist and client to look directly at each other. Correct positioning is always difficult for the interpreter, and there is no single correct position. There are also pros and cons to every position. Haffner et al. (2003:4) point out that if the interpreter sits next to the client, the provider can see both the patient and interpreter, which means that the client is likely to speak directly to the provider. There is, however, the risk that an alliance may form between the client and the interpreter which might exclude the therapist:

[T]his arrangement may encourage a reticent patient to be more forthcoming because the interpreter's presence at the patient's side may be felt as supportive. The downside to this position is that the provider may tend to look at the interpreter instead of the patient. The patient may view the interpreter as an ally and might try to confide in the interpreter or seek the interpreter's advice. Patients may be more inclined to make side comments to the interpreter. In addition, some patients just do not speak to the provider and will actually turn around to talk to the interpreter at their side. (Haffner et al. 2003:4)

The advantage of sitting in the middle, between the provider and the client, is that the client and provider are more likely to see the interpreter as an unbiased participant (Haffner et al. 2003:4). In the second role play, the trained interpreter took notes to aid memory, often looking down at them. This, coupled with her positioning between the other two participants, arguably contributed to the perception that she was a more neutral co-participant, enabling the client and therapist to focus on each other and not the interpreter, and promoting direct communication between them.

In the next section, I discuss the comments made by the workshop participants in more detail. 


\subsection{Commentary by workshop participants on role play demonstrations}

The two role play demonstrations raised a number of issues in the minds of the workshop participants. A key question that arose was whether interpreters should efface themselves or act as "co-counsellors". The differing positioning and eye gaze in the two role plays provoked a great deal of discussion. The workshop participants discussed what effect this had on the communication process, including the question of whether the allegiance of the interpreter should be with the therapist or the client. They debated at length whether it was correct for interpreters to efface themselves, and some were of the view that the trained interpreter in the second role play was not engaging with the process. They felt that the refugee interpreter in the first role play had a greater rapport with the client than the trained interpreter did in the second role play. It should perhaps be pointed out here that the shared experience of the ad-hoc interpreter and refugee client, in terms of common language and common community, cannot in itself be considered to be therapeutic.

The participants, who were not in a position to analyse linguistic accuracy, also criticised the fact that the trained interpreter took notes during the role play, and felt that the different positioning plus the lessening of eye contact as the interpreter took her notes was "distancing", and meant that the interpreter was "not engaging, not able to co-counsel". They felt that her rendition was "too unemotional, did not reflect the emotions". Interestingly, the counsellor who participated in both role plays commented that she felt much more included in the process during the second role play with the trained interpreter. This was not surprising, since the fact that the trained interpreter effaced herself through positioning, eye gaze and note-taking meant that it was possible for a rapport to form between the refugee client and the therapist instead of between the client and the interpreter, as was the case in the first role play.

After watching the role play with the trained interpreter, the ad-hoc interpreter commented that she had not realised that the interpreter has to interpret everything and should not summarise ("It is important to interpret the thing that the client is saying."). She also commented on the trained interpreter's use of the first person. The other participants agreed that these aspects could be incorporated into an interpreted therapeutic interview.

All of the participants agreed that they had learned a number of things about the interpreting process as a result of the workshop, for example that "interpreting is complex, just speaking another language is not enough", that culture, emotion and power dynamics are important, and that a briefing beforehand might assist in managing the expectations of both parties. The participants agreed that they had been taking the interpreting process for granted, assuming that seamless communication was taking place without being aware of all the factors involved. They agreed that it was important to improve supervision and to include the interpreters in postsession briefings. Some mentioned that viewing the interpreters as co-counsellors might not be the only position to take, since an interpreter has a great deal to think about without trying to counsel as well.

In the next three sections, I discuss role allocation and attribution, turn length and turn control, and linguistic accuracy in more detail, after analysing the transcripts of the two role plays. My findings will then be correlated with the workshop commentary. 


\subsection{Role allocation and attribution: Alliance and 'alienation'}

A second point of discussion during the workshop was the attribution of roles and the question of allegiance, and whether the trained interpreter was correct in her use of positioning and eye gaze (perceived as distancing by the participants), in contrast to the refugee ad-hoc interpreter, who they believed had a better rapport with the client. The opening sequence in the first role play with the ad-hoc interpreter proceeded as follows:

\begin{tabular}{|c|c|c|}
\hline Time & Participant & Script \\
\hline $\begin{array}{ll}00: 00: 00 & - \\
00: 00: 16 & -\end{array}$ & Professional & $\begin{array}{l}\text { My name (gesture) is Susan } 1 / / I^{\prime} m-I^{\prime} m \text { going to be your counsellor// and um // } \\
\text { I just want to say um uh / this is our first meeting so / I wonder how um / what } \\
\text { your needs are / and how we can help you / better um in counselling // (sits back) }\end{array}$ \\
\hline $00: 00: 17$ & Interpreter & Jambo. (Lit. Hello) \\
\hline 00:00:18 & Client & Jam'sana. (Lit. Good morning) \\
\hline $\begin{array}{l}\text { 00:00:19- } \\
00: 00: 32\end{array}$ & Interpreter & $\begin{array}{l}\text { (Counsellor sits back) }{ }^{2} \text { Lit. My name is Camille // I am going to translate from } \\
\text { Lingala // I am going to interpret for her (gesture) }\end{array}$ \\
\hline
\end{tabular}

Figure 2. Opening/lead-in by ad-hoc interpreter in first role play

The counsellor introduces herself to the refugee client and then sits back to wait for the interpretation. The ad-hoc interpreter, who is positioned next to the refugee, as explained earlier, turns to look at him, thus excluding the counsellor from the interaction, and greets him in Swahili. The client returns the greeting, and then the interpreter introduces herself in Lingala, giving her name and saying that she will be interpreting for "her" (the counsellor). The use of the third person to refer to the counsellor as well as the fact that the interpreter does not interpret what the counsellor says, but instead introduces herself and gives her name, has an alienating effect for the counsellor, who would naturally feel excluded from the interaction, and sits back because she does not understand the proceedings. At the same time, the ad-hoc interpreter has managed to create an alliance between herself and the client.

In contrast, as can be observed in Figure 3 below, the trained interpreter briefs both parties in both languages, explaining that she will interpret everything that is said, she will remain neutral and maintain confidentiality, and also that she will use a hand gesture to stop the speaker if too much information is given and she is in danger of forgetting the details of what has been said. The briefing statement has a procedural function - in speaking to both parties in turn and interpreting everything that she herself says, the interpreter is in fact demonstrating to both parties how she means to proceed. The briefing statement has the effect of explicit nonalignment with either party as well as making the role delineation clear. The interpreter also uses the first person when speaking as the client or the professional, which removes the distancing effect of the third person usage by the ad-hoc interpreter. This particular briefing statement is perhaps slightly longer than the norm, but the entire exchange takes only about a minute. The briefing statement is a standard way for trained liaison interpreters to brief both parties and try to avoid certain problems from occurring. Tebble (1999:84) terms this the "contract" - the stage at which the interpreter can provide his/her briefing statement explaining

\footnotetext{
${ }^{1}$ All names appearing in the transcripts have been anonymised to protect the identities of the participants in this study.

${ }^{2}$ The Lingala portion was not transcribed here.
} 
his/her role. The interpreter may also choose to state his/her ethics of impartiality, and assure both parties of his/her intention to maintain accuracy and confidentiality (Tebble 1999:84).

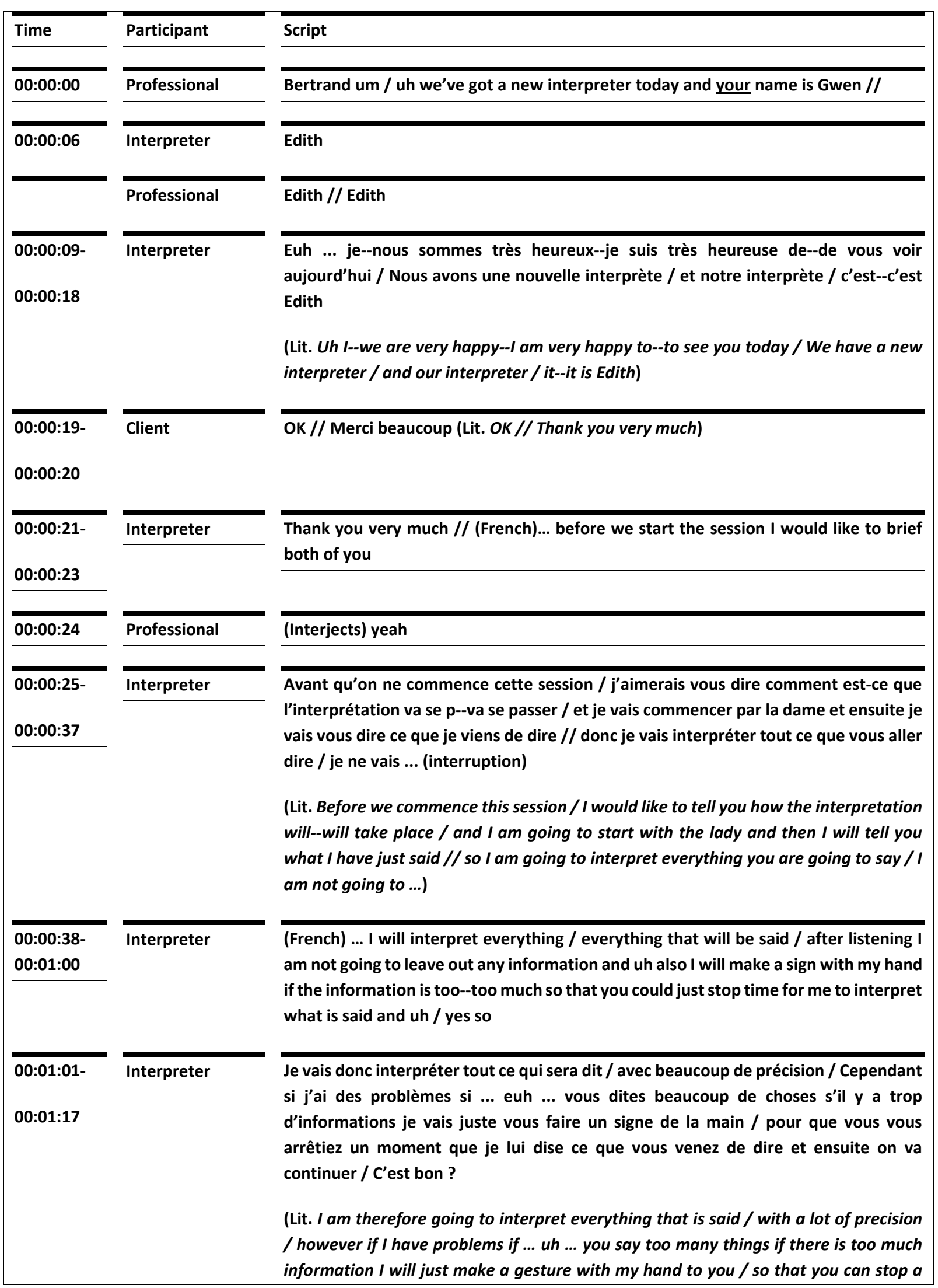




\begin{tabular}{|c|c|c|}
\hline & & $\begin{array}{l}\text { moment and I can tell you what she has just said and then we will continue / Is that } \\
\text { all right?) }\end{array}$ \\
\hline 00:01:18- & Client & OK/ Merci (Lit. OK / Thank you) \\
\hline 00:01:19 & & \\
\hline 00:01:20 & Interpreter & Thank you \\
\hline
\end{tabular}

Figure 3. Opening/lead-in including briefing statement by trained interpreter (second role play)

\subsection{Turn length and turn control}

Giving an explicit brief in which using a hand gesture to stop the speaker is mentioned is a very useful technique, since it makes it possible for the interpreter to control the turn length. In this way, she can ensure that no turn is too long for her to remember and then render it accurately in the other language. A cursory look at the turn length of the four turns which were longer than 10 seconds in duration (in Figure 4) demonstrates that the ad-hoc interpreter's turn is substantially shorter than the original turn in each case.

\begin{tabular}{|c|c|c|c|}
\hline $\begin{array}{l}\text { Participant (client) turn } \\
\text { timings }\end{array}$ & $\begin{array}{l}\text { Duration of original ST turn } \\
\text { (seconds) }\end{array}$ & $\begin{array}{l}\text { Duration of interpreted turn } \\
\text { (seconds) }\end{array}$ & $\%$ of original length \\
\hline 00:00:01- 00:00:56 & 55 & 32 & $32 / 55=58 \%$ \\
\hline 00:01:33 - 00:02:18 & 45 & 28 & $28 / 45=62 \%$ \\
\hline 00:03:06 - 00:03:56 & 50 & 15 & $15 / 50=30 \%$ \\
\hline 00:04:22 - 00:05:11 & 51 & 23 & $23 / 51=45 \%$ \\
\hline
\end{tabular}

Figure 4. Length of interpreted client turns as percentage of original turns (ad-hoc interpreter)

This would seem to indicate that the ad-hoc interpreter was unable to control the turn length of the participants, which resulted in a lack of accuracy as a result of memory overload. For an untrained interpreter, turns of 50 seconds or longer could be deemed too long. In contrast, the turns in the second role play were much shorter as the trained interpreter controlled the length of the turn with a hand gesture. The longest turn during the second role play was 22 seconds, which the trained interpreter rendered in 26 seconds. Of the three turns recorded that were longer than 10 seconds in duration, the interpreter either took slightly longer to render them than the original, or very slightly shorter (11 seconds as opposed to 13 seconds in the original) (see Figure 5). 


\begin{tabular}{|c|c|c|c|}
\hline Participant turn timings & $\begin{array}{l}\text { Duration of original ST turn } \\
\text { (seconds) }\end{array}$ & $\begin{array}{l}\text { Duration of interpreted turn } \\
\text { (seconds) }\end{array}$ & $\%$ of original length \\
\hline 00:01:20 - 00:01:32 (P) & 12 & 14 & $14 / 12=116 \%$ \\
\hline 00:01:48 - 00:02:01 (C) & 13 & 11 & $11 / 13=85 \%$ \\
\hline 00:02:14 - 00:02:36 (P) & 22 & 26 & $26 / 23=113 \%$ \\
\hline
\end{tabular}

Figure 5. Length of interpreted turns as percentage of original turns (trained interpreter)

\subsection{Linguistic accuracy}

An examination of the transcript of the first role play revealed that the ad-hoc interpreter made a number of grammatical errors in both English and French. This, coupled with some trouble in finding the correct term when interpreting (for instance, her inability to find the English term for deporté (lit. 'deported')) and her problems in remembering all the details and controlling the speaker, meant that the flow of communication was rather disjointed in parts. The ad-hoc interpreter also made use of explicitation or labelling in her interpretation of two consecutive turns, in other words, making general phrases or questions made by either the client or the counsellor more precise or explicit. For instance, the counsellor asks:

What um / I just want to get an idea of how that is making you feel today // what is going on for you at the moment //

The counsellor's question is general, aimed at eliciting more information, while obliquely referring to past trauma ("that"). However, the interpretation below by the ad-hoc interpreter makes specific mention of Lindela, a refugee camp, and a specific comparison between the refugee's current state of mind compared to his feelings when he was incarcerated at the refugee camp at Lindela, thus in effect changing the counsellor's line of questioning without the counsellor being aware of this. The ad-hoc interpreter also persists in the use of the third person (c'est pourquoi elle demande (lit 'that's why she is asking')), thus perpetuating the distancing effect between client and counsellor:

Yeah / c'est pourquoi elle demande qu'est-ce que vous sentez maintenant là quand vous êtes assis là-bas par rapport à tout ce qui s'était--qui s'était passé là-bas là où vous étiez à Lindela?

(Lit. Yeah / that's why she is asking what you feel now there when you are sitting there compared to everything that happened over there where you were at Lindela?)

The client then responds to the interpreter's more direct question, explaining his state of mind in a 50-second turn:

Hum c'est quoi // euh / jusqu'à présent euh / euh quand j'essaie un peu de--de penser ou bien de se souvenir de ce qui s'était passé // euh / ça me crée vraiment une colère très approfondie euh / je peux même dire que c'est--je me sens un peu dépressé // euh / je n'arrive quelquefois pas à dormir normalement / euh / au milieu de la nuit quelquefois je / euh / ça fait une situation là où je--c'est comme si quelqu'un vient et 
me--ou bien quelquefois je--je rêve que il y a quelqu'un--il y a les gens qui me--qui me suivent il y a les gens qui veulent me tuer et--et soudainement je vais me réveiller // et vouloir courir ou bien essayer un peu de demander de l'aide / euh // ça--ça m'affecte vraiment //

(Lit. Hmm it's what // uh / up to the present uh / uh when I try a bit to think or even to remember what happened // uh / I experience a really deep anger uh / I can even say that I feel it's--I feel a bit depressed // uh / sometimes I can't sleep normally / uh / in the middle of the night sometimes I / uh / it creates a situation there where I-it's as if someone comes and--or even sometimes I--I dream that there is someone--there are people who are--who are following me there are people who want to kill me and--and suddenly I will wake up // and want to run or try a bit to ask for help / uh // it really affects me //)

The interpreter's turn (below) is only 15 seconds long, and summarises the client's emotions as "every night I've got nightmares":

Ja about that I can say every night I've got nightmares because I can't sleep where every time when I sleep I dream like these people are following me so I feel very depressed and deep anger about what happened //

By failing to interpret the client's exact line of thought into English and labelling the experience as "nightmares", the ad-hoc interpreter has effectively excluded the counsellor from the client's thought-processes, and any insight into the client's state of mind that might have been gained from a more accurate rendition is lost.

A similar situation occurs a second time (in Figure 6) when the client explains that when he sees how the Home Affairs officials in South Africa treat refugees as if they are animals (comme si nous sommes des animaux), he remembers what happened before and states that he wants to go there and do something, a type of revenge (une sorte de vengeance). Again, the interpreter's turn is much shorter, taking less than half the time of the original turn. Apart from omitting a number of details from the first part of the client's turn regarding the process of renewing his visa, as well as the comment about being treated like animals, she labels his feelings of vengeance as "xenophobia times". The interpreter has had to summarise, and labels the entire experience as "xenophobia times", relying on expected formulaic themes rather than the client's actual words. This could be as a result of memory loss, since the turn is too long for an interpreter who is not trained to use notes. Again, the counsellor has no access to the client's actual words, and therefore misses the important reference to wanting to take revenge of some sort. This causes the narrative to become disjointed, and the meaning is no longer coconstructed between client and counsellor. 


\begin{tabular}{|c|c|}
\hline $\begin{array}{l}\text { 00:04:22- } \\
\text { 00:05:11 }\end{array}$ & $\begin{array}{l}\text { Euh / je crois que cette colère vraiment } m \text { 'affecte / euh / et profondément parce que souvent } \\
\text { quand je pars euh / au ministère de l'Intérieur tu vois ici / euh / ils ont un système là où nous } \\
\text { devons euh / nous devons / euh nous devons renouveler nos--le visa surtout nous qui sommes } \\
\text { réfugiés // euh là aussi les--les--la manière dont on traite les gens c'est--c'est--c'est pas vraiment } \\
\text { normal c'est--c'est comme si euh nous sommes les animaux // euh quand--quand je vais là-bas } \\
\text { que je vois comment est-ce que les--les--les agents ou bien les officiers d'émigration traitent ça } \\
\text { me fait mal ça me fait-- ça me fait / euh / se souvenir de ce que j'ai--j'ai--j'ai connu // euh je--je } \\
\text { me sens toujours euh / agressif et je me sens toujours aller là-bas et faire quelque chose une } \\
\text { sorte de--de vengeance // }\end{array}$ \\
\hline & $\begin{array}{l}\text { (Lit. Uh / I think this anger is really affecting me / uh / and deeply because often when I leave uh } \\
\text { / for the Ministry of the Interior (Home Affairs) you see here / uh / they have a system there } \\
\text { where we must uh / we must / uh we must renew our--the visa especially we who are refugees } \\
\text { // uh there too the--the--the manner in which they treat people it is--it is--it is not really normal } \\
\text { it is--it is as if uh we are animals // uh when--when I go there and I see how the--the--the agents } \\
\text { or emigration officers treat it makes me sick it makes me--it makes me / uh / remember what I-- } \\
\text { l--I knew // uh l--I always feel uh / aggressive and I always feel like going there and doing } \\
\text { something a sort of--of vengeance // }\end{array}$ \\
\hline $\begin{array}{l}\text { 00:05:13-00:05: } \\
36 \\
\text { (23 seconds) }\end{array}$ & $\begin{array}{l}\text { Ja every time when I get to Home Affairs / about a renewed papers every time when they treat } \\
\text { us like / they are pushing us / I always feel anger in me I feel like doing something // I always } \\
\text { going there when I think and I see what they are doing at Home Affairs // making me to think to } \\
\text { think back what I've been asking is a favour ... xenophobia times }\end{array}$ \\
\hline
\end{tabular}

Figure 6. Explicitation/labelling by ad-hoc interpreter

In contrast, in the second role play, the trained interpreter employed a number of strategies which assisted her in maintaining accuracy, notably the fact that she controlled the turn length of both parties and employed long consecutive note-taking techniques, both of which minimised memory overload. As a result, she was able to retain the counsellor's line of questioning, avoid labelling or summarising, and maintain the themes introduced accurately. Her level of linguistic skill in both languages is also relatively high, as can be seen from the exchange in Figure 7.

\begin{tabular}{|c|c|c|}
\hline Time & Participant & Script \\
\hline 00:01:20 & Professional & $\begin{array}{l}\text { Thank you um Bertrand I wonder how you have been since I saw you the last time / } \\
\text { when you began to tell me the story and I know I did not get the whole story but I'm } \\
\text { wondering how you were feeling during the week }\end{array}$ \\
\hline $\begin{array}{l}\text { 00:01:33- } \\
\text { 00:01:47 }\end{array}$ & Interpreter & $\begin{array}{l}\text { Euh // Bertrand j'aimerais savoir comment vous vous êtes port--comment vous vous } \\
\text { portez et comment vous êtes--vous vous êtes porté depuis la dernière fois que nous } \\
\text { nous sommes vus / C'est vrai que vous m'avez raconté votre histoire et je n'ai pas } \\
\text { vraiment compris toute l'histoire mais j'aimerais bien savoir comment vous vous } \\
\text { portez aujourd'hui } \\
\text { (Lit. Uh // Bertrand I would like to know how you were feel--how you were feeling } \\
\text { and how you--how you felt since the last time we saw each other / It is true that you } \\
\text { have told me your story and I didn't really understand the whole story but I would } \\
\text { really like to know how you are feeling today) }\end{array}$ \\
\hline $\begin{array}{l}\text { 00:01:48- } \\
\text { 00:02:01 }\end{array}$ & Client & $\begin{array}{l}\text { Euh / je me porte un peu / euh / un peu bien / euh // différemment de ce que je me } \\
\text { sentais la fois--la fois passée // euh parce que c'était vraiment une situation que je } \\
\text { n'ai jamais partagée avec quelqu'un d'autre }\end{array}$ \\
\hline
\end{tabular}




\begin{tabular}{|c|c|c|}
\hline & & $\begin{array}{l}\text { (Lit. Uh / I am feeling a bit / uh /a bit good / uh // differently than that which I felt } \\
\text { the--the last time // uh because it was really a situation that I have never shared with } \\
\text { anyone else) }\end{array}$ \\
\hline 00:02:02 & Interpreter & $\begin{array}{l}\text { Uh I'm fine today / and uh / since last time I've been feeling better because I've been } \\
\text { talking to you and I talk to you about things that I never shared with anyone else } \\
\text { before. }\end{array}$ \\
\hline 00:02:14 & Professional & $\begin{array}{l}\text { Okay, okay it's a big privilege for me to hear your story and I want you to know that } \\
\text { // because there are no two people who have the same story / and um uh I am } \\
\text { wondering how your anger is at the moment where / uh you say you feel better and } \\
\text { it was good to tell me your story // So I am wondering what's happening to your } \\
\text { feelings as well? }\end{array}$ \\
\hline $\begin{array}{l}\text { 00:02:37- } \\
\text { 00:03:03 }\end{array}$ & Interpreter & $\begin{array}{l}\text { Euh // I wou... / je voudrais que tu saches que ça a vraiment été un privilège pour moi } \\
\text { de partager ton expérience et / euh / je ne connais personne qui ait vraiment vécu } \\
\text { la--la--la même expérience que toi / Donc je voudrais savoir en ce qui concerne ton-- } \\
\text { ta--ta colère / comment est-ce que // euh / comment est-ce que tu te portes sur le } \\
\text { plan de la colère? // Comment est-ce que tu te sens par rapport à cette colère? // } \\
\text { C'est ce dont j'aimerais qu'on--que l'on parle aujourd'hui / et je pense que ce serait } \\
\text { bien qu'on en parle // } \\
\text { (Lit. Uh // I wou- / I would like you to know that it was really a privilege for me to } \\
\text { share your experience and / uh / I do not know anyone who has really lived the--the- } \\
\text {-the same experience as you // So I would like to know as regards your--you--your } \\
\text { anger / how do you // uh / how do you feel as regards this anger? // How do you feel } \\
\text { as regards this anger? // That is what I would like us to talk about today / and I think } \\
\text { it would be good to talk about it //) }\end{array}$ \\
\hline
\end{tabular}

Figure 7. Procedural and linguistic knowledge demonstrated by trained interpreter

In the next section I will attempt to draw together the workshop commentary with the conversation analyses of the role plays conducted after the workshop.

\section{Findings and recommendations}

Firstly, it is important to mention that the concept of a professional development workshop as a way to raise awareness of how to work with interpreters does seem to have merit, and encourages reciprocal learning, reflection and discussion by both counsellors and interpreting trainers. Using role plays circumvents the ethical dilemmas involved in observing authentic therapeutic encounters and, while one might argue that role plays are simulated encounters and therefore are not "real" enough, the preceding analysis shows that the interactions contain sufficient interesting material for the discussion of differences in performance between an adhoc interpreter and a trained interpreter (the proviso being, of course, that two of the three participants in the role play, namely the client and the professional, are experienced participants in therapeutic interactions and are therefore able to lend authenticity to the interaction).

The professional development workshop described in this study provided a forum for counsellors and community workers to reflect on the role of the interpreter in the therapeutic context and to re-examine some assumptions. Many of the participants became aware, possibly 
for the first time, that working through an interpreter alters the counsellor's relationship with the client, and that the interpreter has a great deal of influence on the dynamics of the therapeutic interaction. The counsellor in the role play was able to evaluate the difference between working with an ad-hoc refugee interpreter (who, it must be said, had a great deal of experience in this type of setting) and working with a trained interpreter, who had little therapeutic experience but a great deal of procedural knowledge of liaison interpreting. While the majority of the workshop participants felt that the trained interpreter was too self-effacing and unemotional, and criticised her use of note-taking by saying that it impacted on her ability to co-counsel, the counsellor who participated in both role plays commented that she felt much more included in the process during the second role play with the trained interpreter. This was not surprising, since the fact that the trained interpreter effaced herself through positioning, eye gaze and note-taking meant that it was possible for a rapport to form between the refugee client and the therapist, instead of between the client and the interpreter, as was the case in the first role play. The trained interpreter's conscious use of note-taking and positioning, plus the attempt to create the impression of impartiality, indicated to the researcher that she was attempting to conform to the general norms of the liaison interpreting profession as learned during training. The workshop participants, not being familiar with these norms, wished her instead to conform to the norms of therapy and act as co-therapist.

The subsequent analysis of the effect of procedural factors on the communication flow, such as the control of turn length, attribution of roles and briefing of participants, use of the first person, memory management and overload, provides a clear explanation for why the counsellor felt more included in the process when using a trained interpreter. In the second role play, the trained interpreter's knowledge of the procedural aspects, coupled with her linguistic prowess, led to a smoother communication flow. She was able to control the turn length and take notes to avoid memory overload, thus avoiding labelling or summarising, and enabled an accurate rendition of the counsellor's line of questioning. Her briefing of the participants was an important aspect of her management of her role as interpreter.

The perceptions of the workshop participants that the ad-hoc interpreter had a greater rapport with the client needed perhaps to be balanced by a greater awareness of the distancing effect of the interpreter's use of the third person on the relationship between the client and the counsellor, which emerged from the conversation analysis. In addition, the fact that the ad-hoc interpreter had not previously been aware of the necessity to interpret everything that was said was borne out in the analysis, where her inability to control the length of the turns, coupled with a tendency to label or summarise, impacted seriously on the accuracy of her rendition. The workshop participants, not being conversant in both languages, were unable to appreciate this.

The lack of verbatim accuracy of the exchanges interpreted by the ad-hoc interpreter might also lead one to ask whether it is possible that the ad-hoc interpreter, herself a refugee, was in fact re-living her own experiences instead of transferring her client's words verbatim into English. Although the interchange between client and ad-hoc interpreter was a role play only, this is a possibility that deserves consideration. As explained earlier, the problem of providing therapy to political refugees is compounded if the interpreter is also a refugee, since there is an added risk that refugee interpreters might tell their own story rather than faithfully re-telling the client's narrative (Miller et al. 2001). This particular analysis would seem to indicate, however, that it was the interpreter's lack of knowledge of interpreting procedures and requirements, and 
the concomitant issues with memory, role management and terminology, that led to lack of accuracy, rather than her transference of the client's story into her own experience.

It seems clear, then, that knowledge of the refugee setting on its own is not sufficient to facilitate smooth communication between a counsellor and his/her client. An interpreter working in this type of setting should possess sufficient linguistic competence to perform the task accurately, as well as sufficient procedural knowledge to brief the participants, control turn length and avoid memory overload. Where it is impossible to employ trained liaison interpreters, ad-hoc interpreters need to receive additional training in how to manage the procedural factors involved in liaison interpreting contexts as well as receiving insight into the special demands of therapeutic contexts, trauma and stress.

In addition, attention needs to be paid to the nature of the counsellor-interpreter relationship in order to improve the quality of the therapeutic interview. Ideally, just as the interpreter needs to be qualified to work in a clinical setting, so the therapist needs to be qualified to work with an interpreter. Developing an effective working relationship which allows both participants to fulfil their roles without role confusion is vital for effective therapy. While the interpreter should be viewed as a colleague and not simply as a channel, it is also important that the interpreter be allowed to focus on performing as a professional interpreter during consultations, and not attempt to act as a co-therapist. Holding pre- and post-consultation briefing sessions would enable the therapist and the interpreter to consult around therapeutic goals, and allow the therapist to draw on the interpreter's linguistic and cultural observations to supplement his or her own clinical judgement.

It would have been beneficial for all parties concerned had a follow-up workshop taken place, where the results of the conversation analysis could have been communicated to the participants. It would then have been possible for the participants to explore their initial perceptions of the ad-hoc interpreter's performance, and to determine whether the lack of accuracy demonstrated subsequently in the analysis would change that perception. In their examination and CA-based analysis of an interpreted speech therapy setting using an untrained interpreter, Friedland and Penn (2003) state the following:

Note that a static checklist of qualities to be aspired to by an interpreter e.g. fidelity (Gile 1995) would not necessarily work in a context such as this one, because there are times when the flow of the interview required the mediator not to translate word for word. Training of interpreters should be context appropriate rather than standard. There are instances (e.g. United Nations) where an absolute verbatim translation is essential. There are other contexts where in the interests of factors such as time, trust, agendas, such a goal is unnecessary and indeed an inhibitor.

Their comment is relatively typical of professionals who are not trained interpreters, and indicates a lack of awareness of a number of factors, most notably the fact that conference interpreting and liaison interpreting are different types of interpreting, and that training of interpreters is in fact context-specific and not standard. Evaluations of quality in modern interpreting schools do tend to be context-specific. For instance, conference interpreters (who may later work at the United Nations, Pan-African Parliament, etc.) are assessed on their ability to transfer a complex, fast-paced conference speech into the other language in the simultaneous mode of interpreting, whereas liaison interpreters (who may later work in healthcare, 
therapeutic or legal settings) are evaluated on their ability to manage the interpreter's role and the participants' expectations as well as their mastery of procedural factors such as turn control and note-taking in the short and long consecutive modes. Trainers do not advocate word-forword interpretation in either setting - languages are not isomorphic, and it is the transfer of meaning that is key for every interpreter, not the transfer of individual words. Overall faithfulness to the message is, however, non-negotiable within the constraints of each setting, and interpreters must take into account the purpose of the communication and the sender's intentions. Pöchhacker (2002:96-97) states the following on the subject of quality in interpreting:

There is considerable agreement in the literature on a number of criteria which come into play when assessing the quality of interpreting. While the terminology may vary from one author or text to the other, concepts such as accuracy, clarity or fidelity are invariably deemed essential. [...] [T] he interpreter is essentially expected to "represent fully" the original speaker in his/her interests and intentions (Cf. Gile 1991:198) [...] Quality essentially means "successful communication" among the interacting parties in a particular context of interaction.

\section{Conclusion}

To conclude, it would seem that it was the ad-hoc refugee interpreter's lack of knowledge regarding the procedural aspects of the interpreting process that had the greatest negative impact on the communication, rather than her refugee status and possible transference or re-telling of her own story, as has previously been indicated in the literature. It is recommended that professionals using interpreters improve their knowledge of the impact of the interpreting process on therapeutic situations. Equally, interpreters employed in therapeutic contexts should be trained to participate as active co-participants so that they may control turn duration and extend their memories, which will then enable them to interpret accurately in the long consecutive mode with the aid of notes, as well as to deal with role attribution and positioning. Only then will the pragmatic power of interpreters be properly harnessed, and not hampered by lack of technique.

\section{References}

Anthonissen, C. 2010. Managing linguistic diversity in a South African HIV/AIDS day clinic. In B. Meyer and B. Apfelbaum (eds.) Multilingualism at work: From policies to practices in public, medical and business settings. Amsterdam: John Benjamins. pp. 107-139.

Arminen, I. 2005. Institutional interaction: Studies of talk at work. Aldershot, UK and Burlington, USA: Ashgate Publishers.

Belvedere, F., E. Mogodi and Z. Kimmie. 2003. National refugee baseline survey: Final Report. Johannesburg: Community Agency for Social Enquiry (CASE), Japan International Cooperation and United Nations High Commissioner for Refugees.

Bot, H. 2005. Dialogue interpreting in mental health. Amsterdam and New York: Rodopi. 
Cambridge, J. 1999. Information loss in bilingual medical interviews through an untrained interpreter. The Translator 5(2): 201-219.

Deumert, A. 2010. 'It would be nice if they could give us more language': Serving South Africa's multilingual patient base. Social Science \& Medicine 71(1): 53-61.

Drennan, G. 1998. Language and the role of interpreting in South African psychiatry: A study of institutional practice in the Western Cape. Unpublished $\mathrm{PhD}$ thesis, University of Cape Town.

Drennan, G. 1999. Psychiatry, post-apartheid integration and the neglected role of language in South African institutional contexts. Transcultural Psychiatry 36(1): 5-22.

Figley, C.R. 1995. Compassion fatigue: Toward a new understanding of the costs of caring. In B.H. Stamm (ed.) Secondary traumatic stress: Self care issues for clinicians, researchers and educators. Lutherville, MD: Sidran Press. pp. 3-28.

Friedland, D. and C. Penn. 2003. Notes and discussion. Conversation analysis as a technique for exploring the dynamics of a mediated interview. International Journal of Language \& Communication Disorders 38(1): 95-111.

Haffner, L., K. Ruschke, S. Bidar-Sielaff, M.-P. Avery, B. Downing, C. Green and C. Roat. 2003. Guide to interpreter positioning in health care settings. The National Council on Interpreting in Health Care. Available online: http://www.ncihc.org (Accessed 5 September 2013).

Hamerdinger, S. and B. Karlin. 2003. Therapy using interpreters: Questions on the use of interpreters in therapeutic setting for monolingual therapists. Available online: http://www.mh.alabama.gov/downloads/MIDS/DS70703 TherapyUsingInterpretersQuestions UseInterpretersTherapeuticSettingsMonolingualTherapists.pdf (Accessed 5 September 2013).

Hatton, D.C. 1992. Information transmission in bilingual, bicultural contexts. Journal of Community Health Nursing 9(1): 53-59.

Hetherington, A. 2011. A magical profession? Causes and management of occupational stress in the sign language interpreting profession. In L. Leeson, S. Wurm and M. Vermeerbergen (eds.) Signed language interpreting: Preparation, practice and performance. Manchester: St Jerome. pp. 138-159.

Higson-Smith, C., B. Mulder and S. Masitha. 2006. Human dignity has no nationality: A situational analysis of the health needs of exiled torture survivors living in Johannesburg, South Africa. Unpublished research report. Johannesburg: Centre for the Study of Violence and Reconciliation.

Holland, A.L. and C. Penn. 1995. Inventing therapy for aphasia. In L. Menn, M. O'Connor, L.K. Obler and A.L. Holland (eds.) Non-fluent aphasia in a multilingual world. Amsterdam: John Benjamins. pp. 144-155. 
Jefferson, G. (ed.) 1992. Harvey Sacks: Lectures on conversation, volumes I and II. Oxford and Cambridge, MA: Basil Blackwell.

Jordan, B and A. Henderson. 1995. Interaction analysis: Foundations and practice. The Journal of the Learning Sciences 4(1): 39-103.

Kahn, T. 2013. Most people with mental disorders 'not getting care they need'. Available online: $\quad$ http://www.bdlive.co.za/national/health/2013/06/13/most-people-with-mentaldisorders-not-getting-care-they-need (Accessed 19 July 2014).

Lesser, R. and L. Perkins. 1999. Cognitive neuropsychology and conversation analysis in aphasia. London: Whurr.

Marcos, L.R. 1979. Effects of interpreters on the evaluation of psychopathology in non-English speaking patients. American Journal of Psychiatry 136(2): 171-174.

Meyer, B., B. Apfelbaum, F. Pöchhacker and A. Bischoff. 2003. Analysing interpreted doctorpatient communication from the perspectives of linguistics, interpreting studies and health sciences. In L. Brunette, G.L. Bastin, I. Hemlin and H. Clarke (eds.) The critical link 3: Interpreters in the community. Montreal: John Benjamins: pp. 67-80.

Miller, K., L. Pazdirek, Z. Silber and M. Caruth. 2001. Interpreting in psychotherapy with refugees: The interpreter's experience. Presented as part of a symposium on "Interpreting in Refugee Mental Health Settings" at the 109th Annual Convention of the American Psychological Association, 22-26 August 2001, San Francisco, CA.

Miller, K., G. Worthington, J. Muzurovic, S. Tipping and A. Goldman. 2002. Bosnian refugees and the stressors of exile: A narrative study. American Journal of Orthopsychiatry 72(3): 341354.

Mouyis, E. n.d. The role of interpreters in psychotherapy with refugees: An exploratory study conducted at the Trauma Clinic of the Centre for the Study of Violence and Reconciliation (CSVR). Unpublished MA research report, University of the Witwatersrand.

National Department of Health. 2007. A policy on quality in health care for South Africa abbreviated version. Pretoria: National Department of Health. Available online: http://www.info.gov.za/view/DownloadFileAction?id=94073 (Accessed 18 November 2013).

Penn, C. 2007. Factors affecting the success of mediated medical interviews in South Africa. Current Allergy \& Clinical Immunology 20(2): 66-72.

Pentz-Moller, V. and A. Hermansen. 1991. Interpretation as part of rehabilitation, part I. Torture (3)1: 9-13.

Pfaff, C. and I. Couper. 2009. How do doctors learn the spoken language of their patients? South African Medical Journal 99(7): 520-522. 
Pöchhacker, F. 2002. Researching interpreting quality: Models and methods. In G. Garzone and M. Viezzi (eds.) Interpreting in the 21st century. Amsterdam and Philadelphia: John Benjamins. pp. 95-106.

Pöchhacker, F. 2006. Research and methodology in healthcare interpreting. Available online: http://www.lans-tts.be/img/NS5/pochhacker.PDF (Accessed 18 November 2013).

Roberts, R.P. 1997. Community interpreting today and tomorrow. In S.E. Carr, R.P. Roberts, A. Dufour and D. Steyn (eds.) The critical link: Interpreters in the community. Amsterdam: John Benjamins. pp. 7-25.

Roy, C. 2000. Interpreting as a discourse process. New York and Oxford: Oxford University Press.

Schegloff, E.A. 1987. Between micro and macro: Contexts and other connections. In J.C. Alexander, B. Giesen, R. Münch and N.J. Smelser (eds.) The micro-macro link. Berkeley, CA: University of California Press. pp. 207-233.

Tebble, H. 1999. Training doctors to work effectively with interpreters. In L. Brunette, G.L. Bastin, I. Hemlin and H. Clarke (eds.) The critical link 3: Interpreters in the community. Amsterdam: John Benjamins. pp. 81-95.

Wallmach, K. 2008. Interpreting interaction in HIV/AIDS counselling - a corpus-based study. Paper presented at the International Seminar on Corpus Linguistics "New Trends in Corpus Linguistics for Language Teaching and Translation Studies. In Honour of John Sinclair", 2224 September 2008, Granada, Spain.

Weiten, W. 1995. Psychology: Themes and variations. Pacific Grove, CA: Brooks/Cole Publishing Company.

Westermeyer, J. 1990. Working with an interpreter in psychiatric assessment and treatment. The Journal of Nervous and Mental Diseases 178(12): 745-749.

\section{Appendix: Transcription conventions}

$\begin{array}{ll}/ / & \text { Micropause } \\ \text { Uh/euh } & \text { Pause with falling intonation } \\ & \text { Hesitation }\end{array}$

